\section{IJ§ER}

ISSN: 2149-5939
International Journal of Social Sciences and Education Research

Online, http://dergipark.gov.tr/ijsser

Volume: 3(2), 2017

\title{
Sorumluluk anlamında bireysel ve toplumsal etkileşim
}

\author{
Individual and social interaction in the sense of responsibility
}

\author{
Mehmet Akın ${ }^{1}$
}

Received Date: $01 / 09$ / 2016

Accepted Date: 15 / $01 / 2017$

\section{$\ddot{O} z$}

Insan yaratılmıșlar arasında akıl nimeti sayesinde yaptığ eylemlerden sorumlu tutulan tek varlıktır. Sorumluluğu doğrudan etkileyen bireysel tercihlerin yanısıra toplumsal etkilerin varliğ yadsınamaz bir gerçektir. Bu gerçekle birlikte bireysel ya da toplumsal etkileşim yoluyla hayata geçen davranışlarda sorumluluğun paylaşılması veya ortadan kalkması söz konusu olabilir mi? Sorusu, Kur'an'ı Kerim 'in farklı sure ve ayetlerde ele aldığı ve açıklı$\breve{g a ~ k a v u s ̧ t u r d u g ̆ u ~ b i r ~ m e s e l e d i r . ~ C ̧ a l ı s ̧ m a m ı z ı n ~ a m a c ı ~ s o r u m l u l u g ̆ u n ~ p a y l a s ̧ ı m ı ~ n o k t a s ı n d a ~ i l a h i ~ m e s a j ı n ~ n a s ı l ~ b i r ~}$ yol gösterdiğini tespit etmektir. Toplumda sık sık karşılaştığımız istenmeyen davranışların sebeplerine tutunarak bireysel sorumluluk ve tercihin arka plana itildiği bir anlayış, manevi mesuliyetin giderek zayıflamasina yol açmaktadır.Çalışmamızda tümevarım yöntemi kullanılarak konuyla ilgili farklı surelerdeki ayetler Kur'an'ın bütünlüğ̈̈ ilkesi çerçevesinde ele alınacaktır. Konuyla ilgili ayetlerin muhtemel anlamlarına ulaşmak için farklı yüzyıllarda yaşamıs müfessirlerin görüsslerine yer verilecektir. Özellikte Taberî'nin Camiu-l Beyan'ına, Razî'nin Mefatihu-l Gayb'ina ve gerektiğinde farkl müfessirlerin ayetleri nasll değerlendirdiklerine temas edilecektir.Baskasının sorumluluğunun alınmayacă̆ını ifade eden, Fâtır suresi 35/18, Ankebut suresi 29/12. Ayetleriyle; Ankebut suresi 29/13 ve Nahl suresi 16/25. ayetleri yukarıda ifade ettiğimiz müfessirlerin görüşleri çerçevesinde açıklanmaya çalışılacaktır. Toplumsal ya da bireysel etkileşim sonucunda yapılan davranışların kişiyi ne ölçüde bağladı̆̆l, sorumluluk anlamında ciddi önem arz etmektedir. Bu itibarla Kur'an' neyi ögütlediği müfessirlerin yorumuyla birlikte anlaşılmaya muhtaçtır.

Anahtar sözcükler: Kur'an, bireysel, toplumsal, etkileşim.

\begin{abstract}
Man, among all creatures, is the only one who is held responsible for his deeds due to his wisdom - a gift given by Allah. It is an undeniable fact that there are social factors as well as individual choices affecting responsibilities directly. The question of whether or not to share the responsibility in behaviours through individual or social interaction is an issue handled and explained in differing surahs and verses in the Holy Qur'an. This study aims to show the way divine message follows in terms of sharing responsibilities. Tendency to ignore responsibilities and preferences by leaning on the causes of undesired behaviours, which we often face in the society, leads to the weakening of spiritual responsibilities. The verses in different surahs will be considered in our study in an inductive method and in accordance with the principle of the wholeness of Qur'an. The views of glossators of different periods in history will be included so as to reach the probable meanings of the verses. Camiu-l Beyan by Taberi and Mefatihu-l Gayb by Razi will especially be refered to, and when necessary, other glossators will also be cited. An attempt will be made to explain Surahs Fatir 35/18 and Ankebut 29/12, and Ankebut 29/13 and Nahl 16/25 based on the above mentioned glossators' views. The extent to which behaviours displayed in consequence of social and individual interactions influence people is considerably important. Therefore, what Holy Qur'an recommends in this respect needs understanding with the help of the glossators' comments.
\end{abstract}

Keywords: Qur'an, individual, social, interaction

\footnotetext{
${ }^{1}$ Dr., Ankara Üniversitesi İlahiyat Fakültesi, Ankara/Türkiye, akinmehmet55@hotmail.com
} 
Akın, M. (2017). Individual and social interaction in the sense of responsibility. International Journal of Social Sciences and Education Research, 3(2), 540-548.

\section{Giriş}

\subsection{Araştırmanın problemi}

Bireysel ve toplumsal etkileşim yoluyla insan davranışlarının yönlendirilebiliyor olması ontolojik bir gerçekliktir. Bu gerçeklikle birlikte insanın varoluşsal olarak sorumlu tutulabilmesi için, sorumluluğun asgari şartları olarak kabul edilebilecek tüm donanımlara sahip olması gerekmektedir (Özdemir, 2001, s.263). İşte bunun içindir ki bireysel ya da toplumsal etkileşim yoluyla hayata geçen davranışlarda sorumluluğun kime ait olduğu meselesi tartışma konusu olmuştur. Sorumluluğun tespitiyle ilgili tartışılan bu önemli konuya Kur'an'1 Kerim'in farklı sure ve ayetlerinde değinilmektedir. Ancak konuyla ilgili ayetlerin zahiri anlamlarından birbiriyle zıtlık içeren sonuçlar çıkabileceği dikkatimizi çekmektedir. Bu çelişkileri önlemek için ilgili ayetlerin Kur'an'ın bütünlüğü çerçevesinde ele alınması zorunluluğu ortaya çıkmaktadır. (Teymiye, 1984, c.1 s.110; Cerrahoğlu, 2014, s.57; Albayrak, 2009, ss.4748; Candan, 2014, s.44).

\subsection{Araştırmanın gerekçesi}

Toplumda sık sık karşılaştığımız istenmeyen davranışların sebeplerine tutunarak bireysel sorumluluk ve tercihin arka plana itildiği bir anlayış, manevi mesuliyetin giderek zayıflamasına yol açmaktadır. İlahi mesajın toplumların fiillerini şekillendiren manevi yönünün bu açıdan önem taşıdı̆̆

\subsection{Araştırmanın amacı}

Çalışmamızın amacı sorumluluğun paylaşımı noktasında ilahi mesajın nasıl bir yol gösterdiğini tespit etmektir. Kur'an'1 Kerim'de konu ile ilgili farklı surelerde geçen ayetlerin değerlendirilmesinde ortaya çıkan anlamların bir bütünlük içerisinde ele alınması gerektiğini tespit etmektir. Bu itibarla insani eylemlerin ortaya çıkmasında rolü olan etmenlerle birlikte sorumluluğun tespiti araştırmanın en önemli amacıdır. Toplumsal ya da bireysel etkileşim sonucunda yapılan davranışların kişiyi ne ölçüde bağladığı, sorumluluk anlamında ciddi önem arz etmektedir. Bu itibarla Kur'an'1 Kerim'in bu önemli konuda neyi öğütlediği müfessirlerin yorumuyla birlikte değerlendirilecektir.

\subsection{Araştırmanın yöntemi}

Çalışmamızda tümevarım yöntemi kullanılarak konuyla ilgili farklı surelerdeki ayetler Kur'an'ın bütünlüğü ilkesi çerçevesinde ele alınacaktır. Konuyla ilgili ayetlerin muhtemel anlamlarına ulaşmak için farklı yüzyıllarda yaşamış müfessirlerin görüşlerine yer verilecektir. Özellikte Taberî'nin Camiu-1 Beyan'ına, Razî’nin Mefatihu-l Gayb'ına ve gerektiğinde farklı müfessirlerin ayetleri nasıl değerlendirdiklerine temas edilecektir. Başkasının sorumluluğunun alınmayacağını ifade eden, Fâtır suresi 35/18, Ankebut suresi 29/12. ayetleriyle; Ankebut suresi 29/13 ve Nahl suresi 16/25. ayetleri yukarıda ifade ettiğimiz müfessirlerin görüşleri çerçevesinde açıklanmaya çalışılacaktır. 
Akın, M. (2017). Sorumluluk anlamında bireysel ve toplumsal etkileşim. International Journal of Social Sciences and Education Research, 3(2), 540-548.

\section{Bulgular}

"Türkçe sormak fiilinden türetilen bir kelime olan sorumluluk, hukukta; uyulması gereken bir kurala aykırı davranışın hesabını verme, tazminatla yükümlü tutulma, işlenmiş bir suçun gerektirdiği cezayı çekme anlamına gelmektedir. Âyet ve hadislerde ise; "sorumlu" manasında mesul kelimesi yanında aynı kökten türeyen "sorguya çekilme, sorumlu tutulma" anlamındaki fiiller sıkça geçmektedir”( Yıldız, TDV, 37/381). İnsan davranışlarından sorumlu tutulabilmesi ve davranışların günah ya da sevap olarak nitelendirilebilmesi için kişinin kendi iradesiyle harekete geçmesi gerekmektedir. Bu iradenin yanında davranışa sebep olan dışsal etkenlerin mesuliyet açısından yerinin ne olduğunun tespit edilmesi gerekmektedir. Kur'an'1 Kerim'de farklı sure ve ayetlerde ele alınan bu konuyu, ayetlerde geçen mesuliyet meselesinin zahiri anlamlarını göz önüne alarak "mesuliyet transferi" ve "mesuliyetin bireyselliğgi” adı altında iki başlık altında incelemek mümkündür. Bu itibarla konuyla ilgili ayetlerin zahiri anlamlarının ötesinde müfessirlerin yorumlarıyla birlikte derinlemesine mülahazalar yapılacaktır. Zahirdeki anlamların yanlış yönlendirmeye müsait yönleri, müfessirlerin ilgili ayetleri Kur'an'ın bütünlüğü çerçevesinde yorumlamalarıyla izale edilecektir.

\subsection{Mesuliyet transferi}

Kur'an'1 Kerim'de saptıranlar ve saptırma eylemine sebep olanlar ile ilgili olarak; Nahl suresi 16/25 ve Ankebut suresi 29/13. ayetlerin zahiri anlamlarına tutunarak birbirini etkileyen davranışların ilk bakışta mesuliyet transferi yoluyla başkalarına aktarılabileceği anlamını içeren ifadeler dikkati çekmektedir. Konuyla ilgili ayetlerin zahiri anlamlarının yanısıra müfessirlerin yorumuyla birlikte ilgili diğer ayetleri dikkate alarak değerlendirmemiz gerekmektedir.

Nahl suresi 16/25. ayette: "Kıyamet gününde kendi günahlarının hepsini ve bilgisizce sapıttıkları kimselerin günahlarının da bir kısmını yükleneceklerdir. Dikkat edin, yüklendikleri günah ne kötüdür."

Ankebut suresi 29/13. ayette: “ Onlar, kendi ağır günahlarını ve kendi ağır günahlarıyla birlikte daha nice ağır günahları yüklenecekler ve iftira ettikleri şeylerden de kıyamet günü mutlaka hesaba çekileceklerdir.” buyrulmaktadır.

Günahın mesuliyeti ile ilgili yukarıdaki bu ayetler ilk bakışta zihinde karışıklıklara neden olabilmektedir. Bu ayetlerden başkalarını sapıtma eylemine düşen günahkarların sapıttırdıklarının günahlarından da sorumlu olduğu anlamı çıkmaktadır. Bu ayetleri Taberi ve Razi şu şekilde açıklamaktadır:

Taberî; Nahl suresi 25. ayette geçen insanları doğru olan yoldan saptıran kişilerin, saptırdıklarının günahlarının bir bölümünü de yükleneceklerini ifade etmektedir. Ancak bu ifade, sapanların günahlarının azalacağı anlamına gelmemektedir. Nitekim Taberî burada konuyla ilgili olarak Peygamber efendimizin (sav) bir hadisini nakletmektedir. "Kim, insanları doğru yola davet ederse, ona, kendisine tabi olacak kimselerin mükafatı kadar mükafat vardır. Verilen bu mükafat, onlardan herhangi birinin mükafatını eksiltmeyecektir. Kim de sapıklığa 
Akın, M. (2017). Individual and social interaction in the sense of responsibility. International Journal of Social Sciences and Education Research, 3(2), 540-548.

çağırırsa, ona, kendisine uyan kişinin günahı kadar günah vardır. Yüklenilen bu günah da, onlardan herhangi birinin günahını eksiltmeyecektir" (Müslim, K. el-ÎIm, bab: 16, Hadis No: 2674 ; Ebu Dâvûd, K. es-Sünne bab: 6, Hadis No: 4609; Tirmizi, K. el-îlm, bab: 15, Hadis No: 2674-26-75; Taberî, 1996, 5/195). Taberî benzer anlama gelen Ankebut suresi 13. Ayetin açıklamasında çok fazla yorum yapmazken ayeti kendinden önceki ayetle açıklamaya çalışmaktadır. Onlar hem kendi günahlarını yüklenecekler hem de saptırdıkları kimselere öncülük etmelerinden dolayı günah yükleneceklerdir. Hesap gününde, onlar, dünyada uydurdukları yalanlardan mutlaka hesaba çekileceklerdir. Taberî̀nin bu yorumundan başkalarını saptırma eylemine başvuranların günah kazanacakları ve onları kandırmak için söyledikleri yalanlarından ayrıca hesaba çekilecekleri anlaşılmaktadır (Taberî, 1996, 6/363).

Razî ise Nahl suresi 25. ayeti şöyle açıklamaktadır; Yüce Allah "Saptırdıkları kimselerin veballerinden bir kısmını da yüklenecekler" buyurmuştur. Bu, "O kendisine uyulan kişiler için de, tâbi olanların günahlarının misli kadar" demektir. Burada kast olunan şey, Allah Teâlâ'nın, tâbi olanların hak ettiği o cezayı, tabi olduklarına vermesi değildir. Çünkü bu Allah'ın adaletine yakışmaz. Razî buna delil olarak şu ayetleri ifade etmektedir: "Hakikaten insan için, kendi çalıştığından başkası yoktur." (Necm suresi, 53/39) ve "Hiçbir günahkâr başkasının günah yükünü yüklenmez.”(İsra suresi, 17/15) bu ayetlerden de anlaşılacağı üzere; günaha önderlik yapanlar, insanları yanlışa yönlendiren bir yol açtıkları zaman, cezaları büyük olur. Bu ceza o kadar büyür ki, onlara uyan her bir ferdin hak etmiş olduğu cezanın tamamına denk gelir. (Razî, 1992, 14/198-200). Razî, konuyla ilgili olarak Vahidî'den şunları aktarmaktadır: "Ayetteki, "min evzâri" kelimesindeki min "teb'îz" (bölmek) için değildir". Çünkü bu kelime bu manada olsaydı o zaman, tâbi olanların günahlarının bir kısmı hafifletilirdi. Ancak bu doğru ve adaletli bir durum olmazdı. Nitekim Vahidî, Taberî’nin yukarıda aktardığı hadisi aktararak Hz. Peygamber, "Onların günahlarından herhangi bir şey eksilmeksizin" buyurmuştur. Aksine, bu ifadenin başındaki min, cins ifâde etmektedir. Yani "Onlar saptıranlar, kendilerine uyanların günahlarının cinsinden olan günahları taşıyacaktır." anlamındadır. Onların günahlarının bir kısmını ya da tamamını yüklenecekleri anlamında değildir (Razî, 1992, 14/198-200).

Ankebut suresi 29/13. ayeti ise Razî şu şekilde yorumlamaktadır: "Onlar muhakkak ki kendi yüklerini de, o yükleriyle beraber daha nice yükleri de bizzat yüklenecekler ve uydurmakta oldukları şeylerden kıyamet günü muhakkak ki mesul olacaklardır."

Razî günahkarların uydurdukları şeylerin gerekçelerinden hareketle açıklama yapmaktadır. Onlar, küfürleri sebebiyle günah yoktur şeklinde düşünmektedirler. Dolayısıyla "Sizin günahlarınızı biz yüklenelim”(Ankebut suresi, 29/12) şeklindeki ifadeleri kullanmaktadırlar. Ancak kıyamet gününde bu vadettiklerinin aksi ile karşılaşırlar. Onlar bu uydurdukları şeyden sorgulanırlar. Razî kafirlerin, "sizin günahlarınızı biz yüklenelim" sözünü, haşrin olmadığı şeklindeki inançlarına bağlamaktadır. Kıyamet gününde ise, karşılarına bunun aksi çıktığında, onlar sorguya çekilerek, "siz, haşrin olmadığını iddia etmiş değil miydiniz?" denilir. Onlar, "bizim yolumuza uyun, sizin günahlarınızı biz yüklenelim" (Ankebut suresi, 29/12) dediklerinde, onlara "yüklenin onların günahlarını" denilir, ama onlar hiçbir şey yüklenemez- 
Akın, M. (2017). Sorumluluk anlamında bireysel ve toplumsal etkileşim. International Journal of Social Sciences and Education Research, 3(2), 540-548.

ler. Onun üzerine sorguya çekilerek onlara “niçin uydurdunuz?” denilir. Bu şekilde kafirlerin yalanları ortaya çıkmış olur (Râzi, 1992, 17/607).

Taberî ve Razî’nin ayetleri izahlarından da anlaşılacağı üzerine, toplumda yaygın olduğu üzere işitsel ve görsel iletişim araçları yanısıra sözel ve davranışsal tutumların insanları etkileyen istenmeyen yönlerinin ortaya çıkmasını sağlayan kaynağın sorumluluğu yanında, bireyi mesul kılan yönünün varlığı tartışılmaz bir gerçektir. Küfür ve günah değeri taşıyan istenmeyen davranışların farklı şekillerde zuhur etmesi, bunları yayanların "her türlü sorumluluğu alıyoruz" şeklindeki ifadeleri sorumluluğun transferini asla doğurmayacaktır. Elbette ki bu tip akımlara kaynaklık eden her türlü fiiliyat, Hz. Peygamberin yukarıda zikrettiğimiz hadisi çerçevesinde karşılığını bulacak, tahribat derecesinde cezaya muhatap olunacaktır. Ancak bu, kişinin bireysel tercihiyle yaptığı eylemlerin mesuliyetini hiçbir şekilde ortadan kaldırmayacaktır.

\subsection{Mesuliyetin bireyselliği}

Kur'an-1 Kerim insanı muhatap alan son ve evrensel olma özelliği taşıyan ilahi bir kitaptır. Bu itibarla ilahi mesajın tüm çağlarda insanların hayatlarına rehber olacak nitelikte olmas1, insanların hangi çağda olursa olsun Kur'an'da kendilerine 1şık tutacak telkinlerin varlığıyla mümkündür. Çağımızda insan davranışlarını şekillendiren ve sürekli güncellenen teknolojinin kullanımıyla, sosyolojik ve psikolojik tutumlar gelişmektedir. Her ne kadar dişsal etkenler insan davranışlarını yönlendirebiliyor olsa da, mesuliyet anlamında bireysel tercihlerin önemi Kur'an'da farklı ayetlerde vurgulanmaktadır. Nitekim bu anlama gelen;

Fâtır suresi 35/18. ayette; "Hiçbir günahkar kimse bir başkasının günahını çekmez. Eğer günahı ağır olan bir kişi, yükünü taşımak için bir başkasını çağırsa, akrabası bile olsa yükünden hiçbir şey taşımaz. Sen ancak görmedikleri halde rablerinden korkanları ve namaz kılanları uyarırsın. Kim (günahlarından) arınıp temizlenirse kendisi için arınıp temizlenmiş olur. Nihayet dönüş Allah'adır."

Benzer şekilde Ankebut suresi 29/12. ayette; "Kâfirler müminlere: "Bizim yolumuzu takip edin de, sizin günahlarınızı biz yüklenelim. derler. Oysa onların günahlarından hiçbir şey yüklenmezler. Şüphesiz onlar yalancıdırlar.” buyrulmaktadır. Bu ayetler anlamları itibariyle hiç kimsenin başkasının günah yükünü alamayacağını ifade etmektedir.

Taberî, günahın mesuliyetinin bireyselliği anlamını taşıyan Fatır suresi 35/18. ayeti şu şekilde yorumlamaktadır: Hiçbir günahkar kimse bir başkasının günahını çekmez. Eğer günahı ağır olan bir kişi, yükünü taşımak için bir başkasını çağırsa, akrabası bile olsa günahı ağır olanın yükünden hiçbir şey taşıyamaz. Yüce Allah bu âyeti kerimede, kıyamet gününde herkesin ameliyle baş-başa kalacağını ifade etmektedir. Taberî bu ayeti açıklarken kıyamet günündeki telaşı insanların birbirlerinden dahi kaçacaklarını buyuran, başka bir ayetten örnek vererek betimlemektedir. "O gün insan kardeşinden, ana ve babasından, karısından ve çocuklarından kaçar. O gün herkesin, kendisine yetecek kadar derdi vardır.” (Abese 80/34-37) Dolayısıyla herkes kendi yaptığı ile hesaba çekilecektir (Taberî, 1996, 7/18). 
Akın, M. (2017). Individual and social interaction in the sense of responsibility. International Journal of Social Sciences and Education Research, 3(2), 540-548.

Benzer anlam taşıyan Ankebut suresi 29/12. ayette; kâfirler müminlere: "Bizim yolumuzu takip edin de, sizin günahlarınızı biz yüklenelim." derler. Oysa onların günahlarından hiçbir şey yüklenmezler. Şüphesiz onlar yalancıdırlar. Taberî bu ayeti şu şekilde yorumlamaktadır: Allah'ı inkâr eden kâfirler, iman eden müminlere şöyle diyorlardı. "Siz de bizim yolumuzu takip edin. Öldükten sonra dirilmenin gerçekleşeceğini ve insanların hesaba çekileceğini yalanlayın. Şayet sizler bizim yolumuza tabi olduktan sonra ölüp tekrar diriltilecek olursanız o zaman sizin günahlarınızı biz yükleniriz." Halbuki o kâfirler, kendilerine tabi olanların günahlarından hiçbir şey yüklenmezler. Onlar bu iddialarında yalancıdırlar. Ve kıyamet gününde, dünyada uydurdukları yalanlardan mutlaka hesaba çekileceklerdir (Taberi, 1996, $6 / 363)$.

Razî'nin bu konudaki ayetleri yorumlaması ise şu şekildedir. "Hiçbir günahkâr başkasının günahını yüklenmez. Eğer yükü ağır bir kişi, diğer birini onu taşımaya çağırırsa, bu, akrabası da olsa, kendisine ondan hiçbir şey yükletilmez. Sen ancak, Rabbinden korkmakta olanları, namazı dosdoğru kılanları sakındıracaksın. Kim temizlenirse, sırf kendi faydasına temizlenmiş olur. Nihayet varış, Allah'adır.” Fatır 35/18

Razi bu ayeti yorumlarken önceki ayetlerle bağlantı kurmaktadır. Yüce Allah, doğruyu net bir şekilde delilleriyle zikrederek onları bu konuda tefekkür etmeye, düşünmeye davet etmektedir. Bu itibarla Allah; "Hiç bir günahkâr başkasının günahını yüklenmez" buyurmuştur ki bu, "Günahkâr olan hiçbir nefis, günahkâr olan başka bir nefsin günahını yüklenmez" demektir. Eğer Peygamberimiz, bu tebliğinde yalancı olmuş olsaydı, sizin, onun günahını yüklenmeyeceğinizi bilerek bunu söylemekle, günahkâr olmuş olurdu. Peygamberimizin günahkar olması düşünülemeyeceğinden böyle bir şey mümkün değildir. Yüce Allah ise, sizin ibadetlerinize muhtaç değildir. $\mathrm{O}$ halde düşünün ki doğru yoldan ayrilmanız durumunda hiç kimsenin sizin günahınızı yüklenmeyeceğini bilin. $\mathrm{Bu}$, sizin tabi olduklarınızın "yolumuza uyunuz, biz sizin günahlarınızı taşırız” demeleri gibi değildir (Razî, 1992, 18/393).

Razî konunun anlaşılması için "nefis" ve "günahkar nefis" ayrımını yapmaktadır. Yüce Allah, "hiçbir nefis diğerinin günahını üstlenmez" dememiş, sıfat ile mevsûfu birlikte zikrederek, "hiçbir günahkâr nefis, diğerinin günahını üstlenmez" demiştir. Bu şu anlama gelmektedir: Eğer Allah; "hiçbir nefis, diğerinin günahını üstlenmez" demiş olsaydı, o zaman, günah işleyen her nefsin günahının kendilerini üzdüğü ve günah işleyenlerin, kendisiyle ilgili şaşkınlığa düştüğü anlaşılamazdı. Diğer bir ifadeyle: Bir kimsenin, "Hiçbir nefis başkasının günahını yüklenmez" şeklindeki sözünden, onun hiç bir günah taşımadığı da anlaşılabilirdi. Nitekim günahsız kimse, başkasının günahını taşımadığı gibi, esasen kendisine ait taşıyacağı bir günah ta olmaz (Razî, 1992, 18/393-394).

Razî’ye göre, daha sonra Yüce Allah hiç kimsenin bir başkasının günahını, ne doğrudan ya da dolaylı istek ve talepten sonra taşımayacağına delil olarak, yükü ağır bir kişi "çağırırsa" buyurmuştur. Başkasına ihtiyacı çok olmayan kimse kendi ihtiyacını başkasından bir talepte bulunmaksızın karşılar. Ancak ihtiyaç kaçınılmaz olursa, bu onu, başkasından bir talepte bulunmaya zorlar. Razî ayette geçen "muskale" kelimesini konuyla alâkalı olarak yorumlamaktadır. Yüce Allah, bu kelimeden önce, "Günah işleyen (hiçbir nefis) başkasının 
Akın, M. (2017). Sorumluluk anlamında bireysel ve toplumsal etkileşim. International Journal of Social Sciences and Education Research, 3(2), 540-548.

günahını çekmez” buyurmuştur. Razi bu cümleye göre o şahsın yükünü götürebilecek gücü olduğu için, başkası onun yükünü taşımaz demektedir. Yani kişi aslında yükü taşımak için başkasına muhtaç değildir. Nitekim güçlü kuvvetli bir adam eline taşıyabileceği bir yük alsa, o yükünü taşımasına kimse yardımcı olmaz. Ama yük ağır taşınmasıyla ilgili zorluk ortaya çıktığında etraftan ona yardım edilir. İşte bu sebeple Yüce Allah, "müskale” buyurmuştur ki bu; "başkasının yükünü taşıma, o başkasının o yükün ağırlığından dolayı ihtiyaç olana yardım etme isteğindendir.” Ancak bu istek olmasına rağmen herkes o günde kendi günahlarını taşımakla meşgul olacaktır (Razî, 1992, 18/393-394).

Yüce Allah, günahın üstlenilmesi meselesinde, "bu, akrabası da olsa" kaydına yer vermiştir ki bu, "O günahı taşımak için çağrılan kişi, akrabası dahi olsa günahı yüklenmez" demektir. Buna göre "günahkarın yükünü, düşmanı ya da tanımadığı bir kişi taşımak istemez" denebilir. Bunun için Yüce Allah, "bu, akrabası da olsa” buyurmuştur ki bu; "o yükü taşımaya yöneltecek bütün sebepler bulunsa bile" anlamına gelmektedir. Razi yorumunda yardımc1 olmanın talep edilmesini ve talep edilen tarafın buna gücü yetebilecek düzeyde olmasını vurgulamaktadır. Kendisinden yardım talep edilen kişi, edenin akrabası da olsa, bu talebi karşılamamak ancak bir engelden dolayı olur ki, bu engel her kişinin ağır bir yük altında olmasıdır (Razî, 1992, 18/393-394).

Razî konuyla alakalı Ankebut suresi 29/12. ayeti şöyle açıklamaktadır: O kâfirler, iman edenlere dediler ki: "Bizim yolumuza uyun. Sizin günahlarınızı biz yüklenelim," Halbuki bunların günahlarından hiçbir şey yüklenecek değildirler. Şüphesiz ki onlar yalancıdırlar” Yüce Allah kâfirin "iman ettim" diyenleri, küfre davet ettiğinden bahsetmekte, ilâhî azabın o fitnenin üzerinde olduğunu buyurmaktadır. Kâfir de inanan kimseye, "Hangi şeyden ötürü bu zillet ve işkenceye göğüs geriyorsun? Niçin, bize uymak suretiyle, bu zillet ve işkenceyi başından atmıyorsun?" deyince mümin, "sizin yolunuz hatalıdır. Ona uyarsak Allah'ın azap etmesinden çekiniriz" şeklinde cevap vermektedir. Kafirler ise; "bunda ne hata var? Eğer bir hata varsa, hatası bize aittir biz yüklenelim" dediler. Bunu söylemekle kafirler yalancı oldular. Buna göre sanki onlar şöyle demişlerdir: "Eğer bize tabî olursanız, biz sizin hatalarınızı yükleniriz." Onlar işte bu hususta yalan söylemişlerdir. Çünkü onlar hiçbir şey yüklenmezler (Razî, 1992, 17/606).

Ayette geçen, “yüklenelim” şeklindeki ifade, emir sigasıdır. Aslında emredilen, emredenden başkası olurken bir kişinin hem emreden, hem emrolunan olması nasıl düşünülebilir? $\mathrm{Bu}$ "yüklenelim" ifadesi emir sigası olmasına rağmen, şartla birlikte ceza durumunda olup, "Eğer bize uyarsanız, biz sizin hatalarınızı yükleniriz" anlamındadır. "Falanca, falancadan dolayı yüklendi” ş̧eklindeki söz, yükü verenin yükünün azaldığını ifade eder. Ama eğer onun yükü azalmamış ise, yükleneceğini ifade eden ondan herhangi bir şey alıp yüklenmiş olmaz. Razî işte bu ayette de böyledir demektedir. Onlar müminlerin hatalarını üstlenmemişlerdir. Yani müminlerden hataları kaldırıp almamışlardır. Ama onları yoldan çıkartmaları sebebiyle, günahlar yüklenmişler; müminler de kendi tercihleriyle onlara uymalarından dolayı günahlar yüklenmişlerdir (Razî, 1992, 17/606). 
Akın, M. (2017). Individual and social interaction in the sense of responsibility. International Journal of Social Sciences and Education Research, 3(2), 540-548.

Ankebut suresi 29/12. ayette Allah kafirlerin uydurdukları yalanları net bir şekilde ortaya koymaktadır. Taberî ve Razî’nin de yukarıda belirttiği üzere kafirlerin müminleri kandırmak için başvurduğu "sizin günahlarınızı yüklenelim" ifadesinin yalan olduğu herkesin akrabası dahi olsa kendi hesabı derdine düştüğü kıyamet gününde ortaya çıkacaktır.

\section{Sonuç ve öneriler}

Çalışmamız ortaya koymuştur ki insanların kendi iradeleriyle yaptıkları fiillerin mesuliyeti sadece onların kendisine aittir. Bir başkasının günah ya da sevap işlemesine sebep olacak her türlü fiiliyat bir davranış değeri taşımaktadır. Yönlendirme gücüne sahip davranışın iyi ya da kötü olması, günah ya da sevap olarak karşı1ık bulacağı anlamına gelmektedir. Diğer taraftan yönlendirme gücüne sahip davranış modeli bireysel etkileşimle ortaya çıkan davranış tercihlerinin sorumluluğunu da ortadan kaldırmamaktadır. Bu durum ilahi adaletin tecellisi olarak vazgeçilmez bir unsur olmaktadır. İlahi mesajın bu önemli konu hakkında neyi ögütlediğini değerlendirdiğimizde, mesuliyetin transferi diyebileceğimiz sorumluluğun bir başkasina aktarılmasi anlamına gelebilecek Nahl suresi 16/25 ve Ankebut suresi 29/13 ayetleriyle birlikte bireysellik vurgusu yapan Fatır suresi 35/18 ve Ankebut suresi 29/12. ayetlerin varl1ğı konuyla ilgili çok önemli bir bakış açısını zorunlu kılmıştır. Bu bakış açısı da şudur ki: Kur'an ayetleri anlaşılmaya çalış1lırken bir bütün halinde değerlendirme yapmak, sadece bir ayetten yola çıkarak nihai yorumu yapmamaktır. Bu ilkeden hareketle Kur'an-1 Kerim insanın yaratılma amacına uygun olarak bütün yapıp etmelerinden sorumlu olduğunu vurgulamaktadır. İnsan kendi iradesiyle iyiyi ya da kötüyü seçebilme yetisiyle donatılmıştır. Bu yetiye sahip olan insan, toplum içerisinde ortaya çıkan olumsuz davranışları kendi tercihiyle yaptığı bilincinde olmalıdır. Bu itibarla başkalarının kontrolünde olan olumsuz davranış modeli her ne olursa olsun iradesini kullanan bireyin sorumluluğunu ortadan kaldırmamakta, aksine bireye sevap ya da günah tercihi yapabilecek imkan sunmaktadır.

\section{Kaynakça}

Albayrak, H.(2009), Kur'an 'ın Bütünlüğ̈̈ Üzerine, İstanbul, Şule Yayınları.

Candan, A. (2014), Kur'an Okurken Zihne Takllan Ayetler, İstanbul, Düşün Yayınları.

Cerrahoğlu, İ. (2014), Tefsir Tarihi, Ankara, Fecr Yayınları.

Ebû Dâvûd, Süleymân b. el-Eş’as b. İshâk es-Sicistânî el-Ezdî (2000), Sahih-i Sünen-ü Ebu Davud, Riyad, Mektebetul Mearif.

Yıldırım, S. - Cebeci, L. - Kılıç, S - Doğru, C. S. , Ebu Abdillâh (Ebü'l-Fazl) Fahrüddîn Muhammed b. Ömer b. Hüseyn et-Taberistânî er-Râzî Tefsir-i Kebir, (1992) terc. Ankara, Akçağ Yayınları.

Aytekin, K. - Karakaya, H. , Ebû Ca'fer Muhammed b. Cerîr b. Yezîd el-Âmülî el-Băgdâdî et-Taberî Tefsiri (1996), terc., İstanbul, Hisar Yayınları.

et-Tirmizî, Ebû Îsâ Muhammed b. Îsâ b. Sevre (Yezîd) (1995), Cami'u's Sahih, Beyrut, Kitabu-1 Fikr.

İbn Teymiye, Takiyyuddin, (1984), Dekâiku't-Tefsîr, tah. Muhammed es-Seyyid el-Culeyned, Muessesetu Ulûmi'l-Kur'ân, II. Baskı, Şam-Beyrut.

Müslim, Sahih, K. el-ÎIm, bab: 16.

Özdemir, M. (2001), İslam Düşüncesinde Kötülük Problemi, İstanbul, Furkan Yayınları.

Y1lsı, K. "sorumluluk” İslam Ansiklopedisi, TDV Yayınları. 
Akın, M. (2017). Sorumluluk anlamında bireysel ve toplumsal etkileşim. International Journal of Social Sciences and Education Research, 3(2), 540-548.

\section{Extended abstract in English}

Man, among all creatures, is the only one who is held responsible for his deeds due to his wisdom - a gift given by Allah. It is an undeniable fact that there are social factors as well as individual choices affecting responsibilities directly. The question of whether or not to share the responsibility in behaviours through individual or social interaction is an issue handled and explained in differing surahs and verses in the Holy Qur'an. This study aims to show the way divine message follows in terms of sharing responsibilities. Tendency to ignore responsibilities and preferences by leaning on the causes of undesired behaviours, which we often face in the society, leads to the weakening of spiritual responsibilities. The verses in different surahs will be considered in our study in an inductive method and in accordance with the principle of the wholeness of Qur'an. The views of glossators of different periods in history will be included so as to reach the probable meanings of the verses. Camiu-1 Beyan by Taberi and Mefatihu-1 Gayb by Razi will especially be refered to, and when necessary, other glossators will also be cited. An attempt will be made to explain Surahs Fatir 35/18 and Ankebut 29/12, and Ankebut 29/13 and Nahl 16/25 based on the above mentioned glossators' views. The extent to which behaviours displayed in consequence of social and individual interactions influence people is considerably important. Therefore, what Holy Qur'an recommends in this respect needs understanding with the help of the glossators' comments. Our work has revealed that the responsibility of the actions of people in their own interests is solely their own. Every act that causes someone else to commit sin or reward is a behavioral value. It means that the behavior with the power of guiding is good or bad, and it will come in the form of sin or reward. On the other hand, the behavior model with steering power does not remove the responsibility of the behavioral preferences that arise in the individual interaction. This situation is an indispensable element of divine justice. When we evaluate what the divine message is about this important issue, we can say that responsibility can be transferred to someone else, which is the transfer of responsibility to someone else. Sura an Nahl 16/25 and Ankebut sura 29/13 with the emphasis on individuality. A very important point of view about the existence of the verses has become compulsory. The point of view is that the evaluation of the Qur'anic verses in an attempt to understand the Qur'an is not merely a verse from the final interpretation. In this first movement, the Qur'an emphasizes that people are responsible for all their actions in accordance with the purpose of creation. Man is equipped with the ability to choose good or bad in his own will. The person who has this capacity should be aware that he / she is doing his / her own preferences for the negative behaviors that arise within the society. In this respect, whatever the negative behavioral pattern under the control of others, it does not remove the responsibility of the individual who uses the will, but on the contrary, the individual offers the possibility to redeem or sin. 